DOI: http://dx.doi.org/10.22201/iie.18703062e.1963.32.764

NOTAS BIBLIOGRÁFICAS 
DOI: http://dx.doi.org/10.22201/iie.18703062e.1963.32.764 
CHARLOT, JEAN. Mexican Art and the Academy of San Carlos. 1785-1915. Foreword by Elizabeth Wilder Weismann. Austin, University of Texas Press (1962).

Desde que el artista pintor Jean Charlot participó en su juventud en el inicio del movimiento de pintura mural mexicana (1922 y años siguientes) no ha dejado de tener un interés especial en nuestro desarrollo artístico. Pruebas de esto son los excelentes estudios que ha publicado sobre artistas del siglo xIx, como Juan Cordero, o del $\mathrm{xx}$, como Diego Rivera.

Ahora la Imprenta de la Universidad de Texas ha editado bellamente el trabajo que nos ocupa, titulado: El Arte Mexicano y la Academia de San Carlos, 1785-1915, con una breve presentación de otra estudiosa de nuestra historia, Elizabeth Wilder Weismann. Dice que nadie antes de Charlot había pensado en los archivos que guarda la Escuela Nacional de Bellas Artes, quien descubrió su extensión e interés. En realidad tiene razón en buena parte, no en toda, pues en lo que se refiere a los tiempos de la Real Academia sí ha sido explorado y aprovechado el Archivo, en diversos trabajos, no así en cuanto al siglo xix. Al dividirse la institución, en 1929, en Escuela de Arquitectura y Escuela de Artes Plásticas, el archivo quedó bajo la custodia de la primera, que en la actualidad se encuentra en la Ciudad Universitaria. La presentación que hace del libro es comprensiva y se extiende a ciertos aspectos de la historia de México.

El texto de Charlot está escrito desde una actitud nacionalista que recuerda los años en que él viviớ en México; en realidad a estas alturas del tiempo creo que se puede tener una mayor comprensión para el arte académico del siglo pasado. Pero el libro tiene ese interés: seguir el desarrollo nacionalista, como lo revelan de inmediato los diferentes capitulos: "Mexicanidad en la Academia"; "Primeros intentos de un Arte Nacional"; "Vuelta a la imagen Colonial"; "La Mexicanidad surge abiertamente". El primer capítulo, "Los comienzos", se refiere a la fundación y primeros tiempos de la Real Academia; las informaciones se basan en diversos autores y en los Estatutos.

Charlot debe haber tenido inédito su manuscrito descle hace años, pues en diversas informaciones se encuentra atrasado, o bien desconoce recientes publicaciones. Ejemplos: que aún (1962) se encuentran en el mismo edificio de la Academia las Escuelas de Arquitectura y de Artes Plásticas, que en verdad se separaron descle 
1929; la Escuela de Arquitectura desde 1954 está en la Ciudad Universitaria, lo que prueba que el manuscrito debe ser anterior a esta fecha. Con franqueza, extraña que no mencione mi libro Arte Moderno y Contemporáneo de México, publicado en 1952. Se refiere a publicaciones anteriores al ocuparse en la introducción de la litografía, pero desconoce las posteriores, en las que se han aclarado problemas que aún discute; no cita los Doctumentos para la Historia de la Lilografia en México (1955), recopilados por Edmundo O'Gorman y con un estudio del que escribe. Tampoco cita la nueva edición del libro de Linati, Trajes Civiles, Militares y Religiosos de México (1956). También parece desconocer mi artículo ilustrado "Dibujos Neoclásicos", publicado en El Hijo Pródigo, en 1943. En fin no quiero insistir en estos y otros aspectos porque seguramente se tomará como arrogancia de mi parte, lo que en verdad es tan sólo extrañeza. Por otra parte Charlot utiliza inteligentemente, adcmás de los datos del Archivo de la antigua Academia y después Escuela, muchos articulos de diversos investigadores aparecidos en los Anales del Instituto de Investigaciones Estéticas.

Aparte de lo anterior, Charlot incluye muchas informaciones descubiertas por é en el Archivo, que dan novedad y originalidad a su historia, que en conjunto resulta de positivo interés y constituye una contribución valiosa a la historia del arte de nuestro siglo xIx. Pero su investigación no para ahí, pues la extiende hasta 1915 $y$, por lo tanto, quedan incluidas informaciones sobre la huelga de 1911, la Escuela de Pintura al Aire Libre en Santa Anita, las primeras actividades de Orozco, Rivera, Siqueiros y otros. Una vez más extraña que no mencione la Autobiografía de Orozco (1945), que editará en traducción al inglés la Universidad de Texas; poclría haber conocido otros textos publicados.

Ciertamente, como dice Charlot, es la primera vez que se ha intentado sincronizar datos del Archivo con los dibujos que guarda la Biblioteca de la Escuela. Y en esta parte el libro tiene un mérito especial por las reproducciones que incluye, casi todas publicadas por primera vez. Hay aquí también algo que aclarar, pues al pie de las ilustraciones de las famosas "Bacantes" de Rebull, en las terrazas del Castillo de Chapultepec, dice Charlot: Now whitewashed; pero, la verdad es que en años pasados fueron cuidadosamente desprendidas del muro, colocadas sobre estructuras metálicas y reinstaladas otra vez en sus sitios originales, como puede comprobar cualquiera que visite hoy día dichas terrazas.

Si Charlot hubiera hecho un nuevo viaje a México y puesto al dia su información bibliográfica, su libro hubiera alcanzado mayor objetividad en ciertos aspectos; mas, todo cuanto se ha dicho no le resta el valor fundamental que tiene.

J. F. 
KUBLER, GEORGE. The Art and Architecture of Ancient America. The Mexican, Maya, and Andean peoples.-Penguin Books (The Pelican History of Art. Z21. 1962).

George Kubler ha dedicado valiosos estudios al arte antiguo de México y de América. Cada uno de ellos constituye un "land mark" en la historiografía del arte americano. Es justo recordar su monumental obra sobre Mexican Architecture of the Sixteenth Century (1948) y el volumen de Penguin Books que dedicó, junto con Martin Soria, al Art and Architecture in Spain, Portugal and their american dominions. 1500-1800 (1959). El distinguido estudioso norteamericano ha producido un nuevo y magnífico volumen del que nos ocuparemos a continuación, titulado The Art and Architecture of Ancient America (1962), en la misma serie de los Penguin Books, editada por Nikolaus Pevsner, The Pelican History of Art.

En la Introducción Kubler explica: "En este libro el tema principal son las obras de ,valor estético... está escrito para aquellos cuyo interés central se refiere a las obras de arte". Y esta finalidad es la que hace el libro excepcional, porque las obras del pasado indigena antiguo de América han sido generalmente consideradas como objetos de interés arqueológico, etnológico o bien histórico cultural, pero raras veces con estimación artística y estética. Me refiero a las grandes interpretaciones del conjunto de las artes de las diferentes culturas indigenas. La obra de Kubler viene a ocupar su sitio como la última en el tiempo, puesto que la anteceden otras similares, como las de Toscano, Pijoan, Kelemen, Westheim y Covarrubias. Cada una de éstas tiene diferente concepción y organización; la de Kubler ofrece una nueva manera de tratar el tema.

El autor decidió considerar las tres áreas geográficas en que florecieron grandes culturas capaces de crear verdaderas obras de arte, la Mexicana, la Maya y la Andina, y revisar cronológicamente los principales monumentos artísticos en cada región. Pero la cronologia constituye un problema y dice: "Mi interés en el estilo impide cualquier organización por periodos evolutivos".

Se ocupa después en otro problema: los origenes de las civilizaciones de la América indigena, refiriéndose a la tesis del difusionismo, o sea la dependencia de otras, orientales y occidentales, y a la poligénesis, es decir el origen independiente de las civilizaciones del Nuevo Mundo. Con buen sentido Kubler parece inclinarse a esta última tesis, mientras no puedan establecerse mayores pruebas que las meras coincidencias formales con obras asiáticas o europeas antiguas.

La revisión que hace de cómo han tratado los historiadores del arte el tema de la Antigua América Indigena es interesante, aunque no incluye a todos los principales. Y surgen una vez más las teorias que son antecedentes, a saber, si las civilizaciones indigenas forman unidad, o si por el contrario presentan características di. ferentes, como sin duda es el caso. Pero Kubler ha tenido la precaución de incluir al principio del libro unas tablas de correlaciones para cada uno de los tres grupos que trata.

Todas las anteriores consideraciones, y otras más, incluidas en la Introducción, tienden a explicar o a justificar la organización que dio al asunto y son de especial interés porque muestran la plena conciencia de los problemas que tiene que enfren- 
tar el historiador del arte, el crítico y el esteta, al ocuparse en las civilizaciones inclígenas de América.

Kubler pasa a considerar Las Civilizaciones Mexicanas, desde el periodo formativo: 1500-500 A. C., hasta la "confederación azteca" y después La Costa del Golfo y las regiones al sur y al occidente de México. Sin incluir juicios de valor -que ya se encuentran implícitos en la selección de las obras- ofrece con brevedad, como era necesario en tema tan complejo resumido en un volumen, todas las informaciones convenientes, cronológicas, técnicas, míticas, históricas, relaciones formales y descripciones, cuidándose de no usar adjetivos, lo que es usual en su personal estilo de historiador del arte. Más bien que influir en el lector con sus opiniones, le presenta el espectáculo de las obras que interesan y lo deja en libertad de juzgar por si mismo. Dentro de cada tema especial trata, clásicamente, las tres grandes artes: Arquitectura, Escultura y Pintura. A veces se ocupa con detalle en las obras, otras hace consideraciones generales que ilustra con ejemplos.

Resulta novedosa su observación de que existe influencia maya en el arte de Tula, debido a la dominación tolteca en Yucatán después del siglo $\mathrm{x}, \mathrm{y}$ aun anteriormente, y considera varios aspectos y formas que se encuentran tanto en Tula como cn Chichén Itza.

En la parte relativa a la arquitectura de "La Confederación Azteca", incluye Kubler mi propio dibujo de la zona central de Tenochtitlán, publicado hace años, lo que me lleva a suponer que le ha convencido mi interpretación del funcionamiento urbanístico de aquella área. Concluye que la arquitectura axteca no fue notable porque haya tenido importantes innovaciones estructurales.

A la escultura azteca le da importancia y hace notar que el poder expresivo fue distintivo de los escultores; por lo demás, apenas si trata con detalle algunas obras y dice: "El carácter primitivo de la vida tribal azteca encontró su más tremenda expresión en las figuras gigantes llamadas Coatlicue y Yolotlicue'. En cuanto a la pintura, se ocupa en general de los "códices" y brevemente de la cerámica.

El estilo olmeca pertenece a la zona del Golfo y se refire a las cabezas colosales, que se distinguen por sus "precisas relaciones anatómicas y por su modelado fielmente visual". Como ejemplo de arquitectura ninguno mejor que la pirámide de Tajin, con sus originales tableros con nichos.

La región al sur de México incluye "El estilo clásico zapoteca" y Monte Albán constituye el conjunta más grandioso de toda América. De los Mixtecas, Mitla es el sitio de importancia. Y según recientes estudios los "códices" mixtecas y la influencia de sus estilos, en relación con la cerámica, tienen una expansión y preponderan. cia antes no conocidas.

"El occidente de México" abarca desde el Estado de Guerrero, y la novedosa cultura de Mezcala, hasta los de Colima, Jalisco y Nayarit, de donde proviene multitud de figuras de cerámica de extraordinario carácter y calidad artística que hoy dia son tan apreciadas por museos y coleccionistas.

En la parte del libro relativa a "Los mayas y sus vecinos" continúa Kubler su exposición, cuidadosamente documentada. Empieza por la arquitectura del Periodo Clásico, como hoy se llama al que antes se conocía como del "Viejo Imperio", que trata por regiones. Sigue con la Fscultura y la Pintura y su entusiasmo se manifiesta, por excepción, al hablar de la ciudad de Piedras Negras. Se refiere de manera general a las obras en jade y a la cerámica. Distingue semejanzas y diferencias entre los 
estilos de la decoración arquitectónica $y$, por último, considera la pintura murat, refiriéndose a clásicos ejemplos, como Bonampak, y a la cerámica pintada con sus diversos estilos.

El capítulo de mayor novedad e interés es el que trata de los maya-tolteca, que dedica casi exclusivamente a Chichén Itza, para insistir y explicar su tesis de que Tula fue "una avanzada colonial de Chichén más que la inversa", basándose en que no hay nada en Tula correspondiente a los primeros periodos del arte tolteca en Chichén. Si bien la tesis tiene apoyo documental hay que tomarla con cierta reserva y estudiarla con atención, pues es contraria a las teorias hasta ahora establecidas y, por lo tanto, original y revolucionaria. Así, "la arquitectura maya-tolteca aparece ahora mucho más cosmopolita" y añade: "Chichén es como Roma, pero Tula es como una guarnición fronteriza". Por último se ocupa en la pintura mural en Chichén y otros sitios, asi como en los "manuscritos", o libros pintados, anteriores a la Conquista, de los cuales sólo tres han llegado hasta nosotros y se conservan en Dresden, Madrid y Paris. Un capítulo final incluye a los vecinos de los mayas, "Las serranias de Guatemala" y la América central oriental, hasta Panamá; las obras de escultura y de cerámica tienen un carácter distinto al maya y al maya-tolteca, más en cambio evocan el arte andino.

La tercera y última parte del libro, dedicada a "Las civilizaciones andinas", incluye “aquellas partes del montañoso borde del norte y del occidente del Continente Sud Americano, donde florecieron tradiciones artisticas durables", y que son tan diferentes de las "mesoamericanas", como lo explica Kubler.

En una especie de fantástico viaje se presentan a la vista las tumbas milenarias de Tierradentro, Colombia; se discuten los estilos de la escultura y los trabajos en metal; se pasa a la costa ecuatorial del Pacifico y de allí a los Andes centrales, al norte del Perú. El conjunto arquitectónico de Cerro Sechín es formidable, tanto como los del norte alto: El Purgatorio, Chanchín -especie de laberinto cretense- y Viracochapampa. La cerámica Mochica revela un gran sentido de dibujo y en las decoraciones aparecen notas de erotismo y de buen humor. Recientemente se ha podido establecer una secuencia: Mochica, Tiahuanaco, Chimú. En el Perú Central, Pachacamac es otro conjunto urbano impresionante.

Uno de los aspectos más atractivos son los textiles de Paracas y la cerámica Nazca. brillantemente colorida. En las montañas del sur y en los alrededores del Lago Titicaca se distingue hoy al estilo Pucara como varias centurias anteriores al de Tiahuanaco. Este famoso conjunto arquitectónico de carácter ceremonial subsiste a pesar de los saqueos de que ha sido objeto por cinco siglos. La cerámica de Tiahuanaco es policroma, como lo fue en su tiempo la arquitectura. Por última en el valle de Cuzco sc levanta la ciudad, cuyo trazado recuerda al de Viracochapampa, en la que los masivos muros del periodo incaico son a menudo fundamento de las construcciones coloniales, si bien dice Kubler que, como las prácticas constructivas continuaron en el periodo colonial, a menudo se ven muros identificados como de la pre-Conquista que en realidad pertenecen a la época colonial. No podía faltar la consideración del fantástico conjunto arquitectónico de Machu Picchu.

En suma, el texto de Kubler presenta al lector no sólo con las obras de arte y arquitectura seleccionadas en cada región: Mexicana, Maya y Andina, sino con consideraciones y problemas históricos y cronológicos bien documentados. Además, las novedades de interpretación que hemos procurado anotar tienen verdadero interćs tanto 
para el conocedor como para el lector que por primera vez haga este viaje por América, con un guía tan seguro, erudito y sensible como es George Kubler.

Los dibujos que ilustran el texto son claros y excelentes, y así también las espléndidas láminas que dan idea de la calidad de las artes objeto del estudio, así como de las notables diferencias entre las obras mexicanas y mayas y, sobre todo, en relación con las andinas.

"El Arte y la Arquitectura de la antigua América", según son presentados por Kubler en el volumen que comentamos, abren la puerta a muchos conocimientos y emociones. La obra viene a enriquecer notablemente la bibliografía de la historia del arte de la antigua América.

\section{J, F.}

WETHEY, HAROLD E. El Greco and his school. Princeton University Press. Princeton, N. J., 1962. 2 vols.

De algunas obras anteriores del doctor Harold E. Wethey, Profesor de Historia del Arte en la Universidad de Michigan, Ann Arbor, nos hemos ocupado ya en estos Anales (No 18, nota sobre Colonial Architecture and Sculpture in Peru. No 26, nota sobre Alonso Cano). Ha estudiado intensamente el arte colonial de Latino América y el arte europeo también. Su obra sobre Alonso Cano es no sólo excelente, sino necesaria para los estudiosos del arte español, como ahora viene a serlo, y en grado sumo, su erudito estudio de la obra de El Greco, que incluye asimismo la de su hijo, Jorge Manuel.

Wethey ha producico esta obra monumental sobrc el gran pintor cretense aclimatado en España, consciente de la necesidad que existía de un estudio crítico, histórico e iconográfico, así como de un catálogo razonado puesto al día. El mismo habla de que la comprensión de El Greco tiene que ser a la luz de los métodos históricos de nuestro tiempo; era urgente distinguir las pinturas auténticas de la mano del artista, de aquellas que salieron de su taller o que son de su escuela, así como de las copias posteriores y de las falsificaciones modernas. Tanto más cuanto que desde 1926 han aparecido muchas obras que fueron desconocidas para cscritores de otros tiempos.

La obra, en dos hermosos volúmenes, tiene tres grandes divisiones: 1, el texto, con apéndices, incluye todo lo esencial y documentado de la biografía de El Greco, sus años en Italia, sus obras maestras en Toledo y las tardías; el capítulo de mayor interćs se titula El genio de El Greco. 2, las reproducciones de las obras y 3, el Catálogo, razonado. El índice de nombres y temas se completa con el de lugares, de gran utilidad.

En la parte dedicada a la biografía Wethey desecha teorias absurdas para aceptar, con buen juicio, sólo aquello que tiene base documental y aclara multitud de aspectos que antes eran desconocidos, o cuando menos borrosos, como las distintas épocas en que habitó en el palacio del marqués de Villena, en Toledo, algo distinto de la llamada "Casa de El Greco", donde el marqués de la Vega Inclán instaló el Museo.

De los años en Italia considera primero, como es natural, el ambiente veneciano y su permanencia en el taller de Ticiano hasta 1570, cuando marchó a Roma. El Greco 
se interesó desde joven por el paisaje, como su maestro y otros, y por la arquitectura; sus composiciones eran conservadoras, pero resintió la influencia de Tintoretto; se formó, pues, como un pintor veneciano. El impacto de Roma aparece más tarde en sus obras en Espana, pero no predomina; Ticiano sigue siendo su guia, aunque también recibe inspiraciones de Correggio. Hábil retratista, a esos años pertenecen los retratos de Giulio Clovio, Anastazi y Porta. Wethey aclara el caso del maestro Domenikos, el supuesto El Greco, y limpia al artista de las innumerables atribuciones que se le han hecho como madonneri, que hoy repudian los historiadores, pues se trata de falsedades, de arte popular y pinturas modernas.

Claramente afirma Wethey que el genio de El Greco surgió en Toledo, deste sus primeras obras para Santo Domingo el antiguo y desde El Espolio, para la sacristia de la catedral, que considera "una cumbre del arte europeo". Su manierismo aparece en el San Sebastión, hoy en la catedral de Palencia, por la postura y el alargamiento de las proporciones del cuerpo. Unos años después resumió todo su poder en $\mathrm{El}$ Entierro del Conde de Orgaz (1586), obra sin antecedentes en la que se encuentru toda la gama de su imaginación creadora. Entre las obras tardías de primer orden están: la Crucifixión en el Prado, el Laocoonte, en Washington, y allí también el San Jerónimo en penitencia. En Nueva York están el Retrato del Cardenal Niño de Guevara y el Paisaje de Toledo.

Como advertimos ya, el capitulo de mayor interés y novedad es el que sc titula El genio de El Greco. Y es su genio lo que puede explicar al artista, como a Rubens, Ticiano, o Miguel Angel, pero como productos de su tiempo. La herencia cretense ha sido exagerada por algunos, dice Wethey, pues su obra proviene del Renacimiento Italiano y del ambiente manierista y religioso español que absorbió en Toledo.

El manierismo en las pinturas de $\mathrm{El}$ Greco tiene su origen en las ideas de Tintoretto y el Veronés; surge en las obras toledanas, en el San Sebastián, El Entierro, La Trinidad, y el San Mauricio. En la Crucifixión del Louvre hay una forma perso. nal del manierismo. $Y$ aquí viene la tesis interesante, pues dice Wethey que: abandona la muscularidad para expresar el espiritu de la Contra-Reforma, el ascetismo; niega el espacio físico y sus composiciones verticales se encuentran en un espacio irreal, sin profundidades visuales, como se ven en el Tintoretto. El Greco es distinto. Combinó el manierismo florentino-romano con el color y la pincelada venecianos. El resultado fue algo completamente suyo. Los cielos no tienen existencia física; $E l E n$ tierro es el triunfo del manierismo. La apariencia no natural del mundo de El Greco, lo extraño de sus ambientes, y la brillantez del color son aspectos de su manierismo mistico, que hay que diferenciar del estilo barroco, patente en el Retrato del Cardenal Niño de Guevara. En cambio manieristas son: el Paisaje de Toledo, El quinto sello, y La Inmaculada. No son los escritos de Santa Teresa, ni las doctrinas de San Ignacio lo que informa a El Greco, éstas se pueden relacionar con el barroco, pero no con el místico manierista que era el pintor. $Y$ Berruguete no es un antecedente suyo, si bien ambos provienen del fondo italiano. Cuando floreció El Greco, no había en España -dice Wethey- maestro que lo igualara. En El Entierro se encuentra una variedad de caracteres, en los retratos, que ni Velázquez llegó a cxpresar.

La fama de El Greco comenzó en los sonetos de Paravicino, Góngora, Cristóbal de Mesa y otros. Con Palomino, Ponz, Llaguno y Amírola y Ceán Bermúdez las opiniones fueron desfavorables al pintor, que acabó por ser olvidado fuera de España hasta la cuarta década del siglo xrx. Baudelaire y Delacroix lo admiraron y Dégas, 
Millet y Rusiñol poseyeron algún cuadro de él. En cambio, los historiadores espanoles seguían llamando a su estilo "extravagante", hasta que Manuel Cossío publicó, en 1908, la primera monografía de la obra y posteriormente se levantó el entusiasmo por El Greco. El caso se comprende porque con los nuevos conceptos del arte del siglo $\mathrm{xx}$ era posible ya, como ha sucedido, reconocerlo como uno de los grandes pintores de todos los tiempos.

Un último capítulo se refiere a las obras de arquitectura que proyectó, o que realizó El Greco, que son altares para Santo Domingo el antiguo y para la Capilla de San José, en Toledo, así como el altar mayor de Illescas y la obra más ambiciosa, cl altar mayor del Colegio de doña María de Aragón, en Madrid, destruído a principios del siglo xix. Otras obras más son de él y otras le han sido atribuidas.

Al final del texto se encuentran las numerosas notas que apoyan las opiniones de Wethey o que las amplian y documentan, 275 en total.

Los apéndices se refieren a: las firmas de El Greco; el Taller y los ayudantes; la Biografía de Jorge Manuel y su obra como arquitecto.

La mitad del primer volumen se destina a las reproducciones, todas en blanco y negro, excelentes. El segundo volumen está dedicado integramente al Catálogo razonado y comienza con unas notas críticas de la bibliografia de El Greco llenas de interés. Todos los conocimientos, experiencia y erudición de Wethey se vuelcan en el Catálogo y con seguro juicio crítico separa las obras auténticas, 285 en número, de las obras de escuela, las copias y las atribuciones erróneas; también incluye los dibujos, auténticos $\mathrm{y}$ atribuidos, asi como las esculturas, buenas $\mathrm{y}$ falsas.

En cuanto a los cuadros de nuestras galerías de pintura, que pertenecieron a la Colección Pani, y algún otro, no son sino copias modernas y el tema es San Francisco en éxtasis.

Los historiadores y los especialistas en El Greco podrán tener opiniones distintas a las de Wethey sobre tal o cual pintura, pero estaran de acuerdo, creo, en que su obra tiene positiva autoridad y en que constituye una contribución de primer orden para la historiografía de la pintura española y la de El Greco en particular, además de ser de gran utilidad. Después de Cossio, de otros más, y de Sohener, la obra de Wethey es hoy por hoy la de mayor importancia que se haya publicado sobre $\mathrm{El}$ Greco y tiene un valor que le dará larga vida.

J. F.

BAIRD, Jr. JOSEPH ARMSTRONG. The Churches of Mexico. 1530-1810. Photographs by Hugo Rudinger. University of California Press. 1962.

El libro de "Las iglesias de México" es el feliz resultado de la relación entre un fotógrafo inteligente $y$ sensible, Hugo Rudinger, $y$ uno de los mejores estudiosos de nuestra arquitectura "colonial", Joseph A. Baird. Hay que comprender desde un principio que Baird tuvo como punto de partida para su trabajo una colección especial de fotografías formada por un viajero interesado en ciertos aspectos de la 
arquitectura de la Nueva España; así, la aprovechó de la mejor manera para formar un erudito Catálogo en directa relación con las láminas. Pero no sólo eso, porque en el texto general que antecede al resto de la obra hace una exposición de ideas sobre el tema, del mayor interés, y, además, completó su trabajo con mapas y dibujos, con tablas cronológicas, con algunas biografías de arquitectos, con un glosario de términos técnicos y con una bibliografía selecta. En verdad no se puede pedir más, y de esa manera Baird ha compuesto una obra importante para los estudiosos y muy útil para el pueblo culto.

Las 155 láminas en blanco y negro están organizadas en orden cronológico y lucen las excelentes fotografías del señor Rudinger. Cierto es quc de algunas iglesias quisiera uno encontrar otros aspectos además de los ilustrados, como, por ejemplo, en Cuitzeo se echa de menos la gran portada; o en el caso del estilo neoclásico, que prácticamente no está ilustrado, salvo por una fotografía. Pero si se considera lo que el señor Rudinger tuvo que viajar y el esfuerzo que representa reunir una colección de fotografías como ésta, original e inédita, se apreciará la contribución hecha por el señor Rudinger, pues sólo con amor y entusiasmo por el tema puede lograrse. Es desafortunado que las ocho láminas a colores sean de tamaño pequeño y poco satisfactorias.

En el Prefacio, Baird se refiere a los escasos estudios serios que existen en idioma inglés sobre la arquitectura religiosa colonial mexicana, así como otros en español producidos por especialistas españoles, y agradecemos que opine respecto del Instituto de Investigaciones Estéticas que ha sido la fuente principal de estudios eruditos; tambien recuerda algún trabajo en francés y otros en alemán. De su texto explica que no deja de lado ninguno de los problemas obvios, sino que intenta hacerlos inteligibles en términos de la erudición contemporánea de la historia del arte. $\mathrm{Y}$ asi es.

Las más interesantes consideraciones se encuentran en la Introducción. Trata primero Baird el tema de "las reminiscencias indigenas" en el arte colonial y las teorías sobre las artes mestizas, y hace dos consideraciones, una estética: que tanto en el mundo indígena como en el español renacentista existia la tendencia de unificar la arquitectura y la escultura ornamental; otra técnica: que la inimitable brillantez de los artesanos y diseñadores mexicanos hizo evolucionar los diseños europeos y esta "disecación" de las fuentes europeas se vio como provinciana y de ahí nació el término "colonial". A veces la técnica produjo obras de carácter local, más que indigena; el resultado fue un sabor mexicano especial. Hay que precaverse contra la idea de que las formas menos sofisticadas sean necesariamente "indígenas". Respecto a las posibles influencias del arte mexicano en España no pueden documentarse, si bien se ha expresado tal suposisión sin base por algunos. En cambio, las formas traídas a Nueva España por diseñadores y artífices itinerantes de varias partes de Europa, se modificaron desde un principio, produciéndose nuevas combinaciones originales. El resultado fue una historia desigual y de gran riqueza formal en su desarrollo.

Esta explicación - dice Baird- debe ayudar a limpiar de ciertas desafortunadas connotaciones a la palabra "colonial", ya que en México se desarrolló una conciencia propia, artística y política, que modificó inevitablemente el gusto y la tradición curopea. El mestizo respondió a una diferente gama de estímulos estéticos, diferentes de los españoles y criollos, pero aun estos se apartaron de la tradición española. 
Importantes fueron los desarrollos artisticos en las provincias, Oaxaca, Guanajuato, Morelia, Puebla y otros sitios dieron sabor regional especial a la arquitectura y el arte de los últimos tiempos. Y Baird opina que la gran división de corrientes estilisticas, del norte y del sur, sugerida por Kubler es dificil de aceptar, pues las excepciones son tantas que el contraste es inconsistente.

Los materiales locales son un factor determinante en ciertos casos, como en el de Lorenzo Rodríguez quien desarrolló un estilo allende las formas españolas y adaptó su experiencia usando materiales nuevos, como en El Sagrario. Al no existir academia ni escuela de arquitectura - hasta la época neoclásica- se eliminó la tiranía estética. Hubo "círculos" en torno a maestros individuales y asi, la situación fue más elística y creadora de lo que podia esperarse en una colonia.

Baird explica bien su observación acerca de que fue rara en México la planeación de masas y espacios interiores y exteriores; las preocupaciones fueron relativas al tra. tamiento ornamental de muros, la concentración de ricas formas en portadas y retablos, lo que forzó el genio de México a un florecimiento especial y dio: uny notable carácter a la arquitectura. La integración de los edificios con su emplazamiento, como en cl barroco europeo, fueron excepcionales en México. La planeación de los conventos del siglo xvı estaba basada en tradiciones cristianas primitivas. El plano de ciudad deł tipo "parrilla" o de "tablero de ajedrez" es de antiguo origen romano y tuvo un paralelo en la planeación renacentista, más desarrollada en el Nuevo Mundo que en el Viejo y coincidente con algunos aspectos del periodo azteca. Las grandes estructuras arquitectónicas en México se situaron en puntos importantes dentro del plano reticular, con, plazas en los frentes o atrás, y con portales sobre las plazas, pero no dependen de una planeación total a la manera del barroco tardío.

Baird opina correctamente que nunca se ha contado el número de iglesias, pero se olvidó de mencionar el serio intento de catalogación iniciado por la Secretaria de Hacienda en 1929, que hizo posibles los Catálogos de Construcciones Religiosas de Hidalgo y Yucatán.

Monasterios, hospitales y colegios tuvieron excelente planeación; los cubos de escaleras fueron con frecuencia de un magnifico carácter. Las capillas abiertas del xvi, las del Rosario del xvir, los camarines del xvir constituyen brillantes aventuras del uso del espacio y de la ornamentación. Un alto nivel del gusto y de la artesania ayudaron a relacionar periodos y estilos distintos. La preocupación por el concepto de grandeza tuvo una asociación con las fuentes del ethos barroco. Sería imposible - đice Baird- definir la innata sensibilidad de los diseñadores mexicanos, pero se pueden señalar ciertas cualidades $e$ intentar ponerlas en un marco coherente. Aunque una sistematización no es conveniente, si puede dividirse la historia del arte virreinal en tres periodos aproximados de construcción, de unos 50 años: de 1530 a 1580 , de 1630 a 1680 y especialmente de 1730 a 1780 .

En el primer capítulo del libro trata Baird el trasfondo español, en que explica lo problemático del término "Churrigueresco", que a lo menos debe entenderse con la connotación de "mexicano"; tampoco le parece adecuado el término de ultrabarroco. En el capítulo segundo, sobre las Iglesias de México, se ocupa de los tipos de edificios: conventos, catedrales, parroquias e iglesias de peregrinación. Yucatán queda fuera de los limites abarcados por el libro. Las catedrales - dice Baird-son fascinantes y documentos de los cambios vitales en tres siglos. Las parroquias, más que "coloniales", pueden igualar otras de España y Europa del siglo xviı. 
Un tercer capítulo sobre "estilos y modas de la ornamentación" tiene particular interés, Baird recorre la historia y observa que hay una dificultad en la nomenclatura, pues no hay acuerdo entre los especialistas y agrega: En Europa y en los Estados Unidos hay más amplia aceptación de los cambios en la terminología de la historia del arte en los últimos 50 años. Pero algunos escritores latino-americanos todavia tienen que comprender todas las implicaciones de lo que se llama Manierismo y Barroco.

En el Catálogo en relación con las láminas es donde Baird vierte su exceleñte erudición de estudioso del arte virreinal $y$, de acuerdo con las fotografias incluidas, detalla algunos monumentos y trata algunas obras de escultura y pintura. Los párrafos que incluye para explicar sintéticamente el Manierismo, el Barroco y demás estilos son claros y suficientes.

En verdad el libro de Baird y Rudinger es una positiva contribución al conocimiento de la arquitectura y del arte de la Nueva España. Su lectura no sólo es recomendable sino necesaria para los estudiosos. La intima comprensión de los problemas, que para los historiadores del arte entrañan las obras que se produjeron durante el periodo virreinal, hace el trabajo de Baird uno de los más lúcidos, interesantes y útiles que se hayan publicado sobre el asunto.

J. F.

ROSENTHAL, EARL E. The Cathedral of Granada. A study in the Spanish Re. naissance. Princeton, N. J., 1961. Princeton University Press.

Sin duda la Catedral de Granada, uno de los monumentos excepcionales de la ar. quitectura europea renacentista, merecía una monografía tan sabia y erudita como la que ha publicado Earl E. Rosenthal. En efecto, el libro tiene positivo interés en dos sentidos; uno por el aparato erudito en que está basado, junto con el Apéndice con 260 documentos; otro por el texto mismo en que el autor desarrolla su convin. cente tesis de que se trata de un monumento del Renacimiento español -"a lo romano"-, si bien es una síntesis de otros antecedentes, concebida genialmente por Diego de Siloe.

La obra está dedicada al benemérito Walter S. Cook, quien además de ser un distinguido hispanista ha sido un formidable promotor de los estudios sobre la historia del arte en los Estados Unidos, bajo cuya guía y estímulo el autor comenzó a trabajar en el tema desde 1948. En la Introducción expone Rosenthal sus objetivos y las cuestiones que se propuso resolver. Dice, con razón y conocimiento, que la historia del monumento la cuentan los documentos mismos y que, por lo tanto, él se ocupa en otras cuestiones históricas, formales, litúrgicas e iconográficas. Considera que la Catedral de Granada es el mayor monumento del Siglo de Oro español y el primer intento de un arquitecto español para proyectar una catedral en estilo Renacimiento.

Divide el autor la obra en tres grandes partes: I. El proyecto de 1528, II. El "estilo romano", HI. El programa. Así, en cierta manera ha invertido los términos, pues 
aparentemente pareceria más lógico empezar por el programa, seguir con el proyecto y considerar al final el estilo en que fue concebido. Sin embargo, su plan tiene ventajas, ya que las razones históricas, litúrgicas e iconográficas que fueron el punto de partida de Siloc, vienen a conocerse cuando el lector se ha familiarizado con el monumento y acaban por revelar los aspectos básicos de la raison d'étre de la Catedral de Granada.

En la primera parte comienza por estudiar los años de 1492 a 1528 , y considera la actuación que tuvo por 1521 Enrique Egas, quien abrió parte de los cimientos; pero su concepción fue, al parecer, dependiente del tipo gótico de la Catedral de Toledo. Lo importante vino a ser el plano renacentista de Siloe y el deseo de Carlos $V$ de tener en Granada el mausoleo para él y su familia. Siloe determinó las caractcrísticas del edificio desde su plano de 1528 hasta su propia muerte en 1569. Diez años después de haberse hecho cargo de la obra estaban terminados los muros a la altura de las capillas, las puertas del Perdón y de San Gerónimo y el primer cuerpo de la torre. Lo original de Siloe es haber combinado el plano basilical de cinco naves con el ábside semicircular y la rotonda al centro con el altar mayor. Todo el interior fue concebido por él en color blanco, con capiteles, molduras y detalles decorativos en oro; el piso debla ser en blanco y negro, la cúpula en azul y las ventanas policromas, de manera que fuera un recinto luminoso.

A su mucrte siguen los continuadores; el proyecto de Velasco para la fachada con dos torres gemelas; las alteraciones del siglo xvir; el cimborrio barroco; las bóvedas "góticas" de la nave; la fachada barroca de Alonso Cano; la cúpula del trascoro.

La segunda parte: El "estilo romano", consiste en una minuciosa discusión en torno a la crítica que se hizo al monumento en el pasado, para ir reafirmando, parte por parte, que se trata una concepción renacentista "a lo romano". Estudia los posibles antecedentes españoles, las analogías con el Renacimiento italiano, que no convencen y sólo encuentra una, la iglesia del Santo Spirito, aunque las soluciones son diferentes; también considera la Anunziata, con la rotonda y el deambulatorio de Alberti; pero concluye que la Catedral de Granada fue una invención de Siloe. Los antecedentes son relativos y remotos en las iglesias cristiano-primitivas.

Tanto el ábside, con su deambulatorio, que no es "supervivencia medieval", como la nave basilical, los machones cruciformes corintios, las bóvedas - no obstante sus ncrvaduras-, las portadas, como la del Perdón -obra maestra del Plateresco-, son de cstilo romano. Asi, frente a otras catedrales italianas o europeas en general, la de Cranada sobresale por su clara y bien fundada idea y Siloe se muestra como un macstro del estilo romano.

Tiene particular interés la tercera parte de la obra, que se refiere al Programa arquitectónico. El tema central de la concepción de 1528 fue Dios encarnado; la catedral está declicada a Nuestra Señora de la Encarnación. Los vitrales fueron dedicados a la Vida de Cristo. En el Santuario seis santos en escultura y las imágenes de Isabel y Fernando, por Mena, agregadas en el siglo xvir.

Toda la catedral es una "declaración de triunfo", desde su emplazamiento en el sitio que ocupó antes la mezquita principal, hasta los arcos triunfales en las puertas más importantes y los túneles en torno al Altar Mayor. "La promesa del perdón" se significó en la puerta de ese nombre. "La expresión de exaltación" se encuentra en el interior, en la atmósfera creada de gozo y promesa, en el blanco y el oro, que sugieren esplendor y optimismo, en suma, todo se refiere a Dios benevolente. 
El Santuatio y el Altar Mayor al centro rompen con la tradición española de plan longitudinal; Siloe eliminó las barreras y aproximó la congregación al altar. La exposición del Santísimo en el altar sin imágenes fue importante porque los monarcas debian tener sus sepulcros frente a El; también tiene el significado de conmemorar la Conquista de Granada y la expiación de las herejías; el cimborrio del altar sugiere la tumba de Cristo y su resurrección.

La catedral tiene semejanzas con el Santo Sepulcro, pero no parece que haya sido un estímulo para Siloe; las coincidencias son de sentido general. Pero tiene importancia la referencia, pues se trata del mausoleo imperial, que significa la promesa de la vida eterna y la victoria de Cristo sobre la muerte. La catedral es el entierro del Emperador y al mismo tiempo un monumento a la victoria de Granada.

En conclusión, Rosenthal dice: el proyecto de Siloe fue original, inico frente a la tradición de España y Europa. Antecedentes que sólo se encuentran en las iglesias cristiano-primitivas. No tiene precedente en Europa la ingeniosa manera en que Siloe integró la rotonda y la basilica, haciendo concurrir lo físico y lo espiritual; transformó la basilica de cinco naves en una forma renacentista. Se trata, pues, de una ligesia de elementos compuestos de modelo romano.

Como puede verse por todo lo dicho, Rosenthal se ocupó principalmente de la concepción de Siloe de la Catedral de Granada; esa fue su intención y el tema de su tesis. De Alonso Cano como arquitecto se ha ocupado en otra obra Harold E. Wethey (Véase Anales, 26). Asi, Rosenthal ha producido un espléndido libro, que es un modelo de investigación y de síntesis.

J. F.

LE M O I N E VILLICANA, ERNESTO. "Historia sucinta de la construcción de la Catedral de Guatemala". México. Boletin del Archivo General de la Nacidn, No 3. 1961.

El excelente y laborioso historiador del Archivo General de la Nación, Ernesto Lemoine Villicaña nos envía su último trabajo publicado en el magnífico Boletin del propio archivo que su digno director, don Ignacio Rubio Mañé y el mismo Lemoine, han mejorado y revitalizado en forma plausible.

Se trata ahora, en el No 3, de la publicación de una Historia sucinta de la construcción de la Catedral de Guatemala, escrita en 1677 por Gerónimo de Betanzos y Quinones, manuscrito que pertenece al Archivo General de la Nación. Publica Lemoine el documento con una oportuna Introducción, muy completa, crudita y necesaria. Nos recuerda a don Martín de Mayorga, Capitán General de Guatemala y después Virrey de México "huyendo despavorido de la metrópoli herida" por los temblores de 1773. ¡Bendito el pavor de Mayorga! pues eso obligó a abandonar la ciudad de Antigua Guatemala y fundar la Nueva, conservando asi América una de las ciudades más bellas y poćticas del mundo: la arruinada Antigua. Así tenemos dos ciudades, dos capitales, 
y gracias a la segunda no se destruyó totalmente la primera, dejándonos esos floridos muros derrumbados de La Concepción o Capuchinas o los trágicos, y únicos en el mundo, de La Recolección.

Todo intento de reconstruir los templos y conventos de Antigua es absurdo y criminal, pues aquí vuelve a ser veraz la frase de Carlos $V$ a los canónigos de Córdoba: "Construis lo que está en todas partes y destruís lo que es único en el mundo", al referirse a la erección de la Catedral católica dentro de la mezquita musulmana. ¿Qué sentido tiene poner bóvedas de concreto a las naves de piedra como en San Francisco? Y se piensa "reconstruir" la Catedral, que sería, a su ve $z$, destruir la ruinosa belleza de esta Catedral única, lo cual sería un error imperdonable y, sobre todo, irremediable. Dejen los hombres actuales lo que la naturaleza y los hombres del siglo xvrn abandonaron como ruina, que los espacios del mundo son infinitos.

La Historia de la Catedral antigüeña de Betanzos y Quiñones es amplia, clara y completa, desde su inicio, en 1669, hasta el 3 de noviembre de 1677 en que da por terminada su relación. "En cuanto a su contenido -dice Lemoine- la relación de nuestro cronista bien podría encabezarse con el siguiente rubro: "De cómo se construía una catedral en Indias en el siglo xvir", lo que hace obvio recomendar $y$ encarecer sus méritos: estos saltan a la vista y el lector los advertirá desde los primeros párrafos. Conciso y apresurado el texto, no muestra desperdicio ni hojarasca. Todo él es una mina de valiosos datos: técnica de construcción, calidad y procedencia de los materiales, costosos, sueldos, etcétera, presentados, además, con amenidad, soltura y un sabor de época que en ningún momento desaparece".

F. de la $\mathbf{M}$.

BONET CORREA, ANTONIO, Iglesias Madrileñas del siglo xvir. Madrid, Instituto Diego Velázquez. 1961.

Tantas fueron las iglesias madrileñas que llegaron a contarse, antes del siglo xix, ciento cincuenta y cinco. Era ciudad, como dijo don Elías Tormo, "más que monárquica y cortesana, esencialmente conventual". De aquí que, con el transcurso del tiempo, fueron derribadas varias docenas de ellas, unas por necesidades urbanísticas imprescindibles y otras por tontería humana. Fue insensato derribar, por ejemplo, Santo Tomás, San Sebastián, Agustinos Recoletos, etcétera, Quedan aún muchas por fortuna, y de las del siglo xvil escribe un estudio el inteligente, culto y dinámico Antonio Bonet Correa, ahora en México explorando nuestro Arte Colonial. Revisa el autor los libros y crónicas referentes al viejo Madrid, así como sus planos, sobre todo el muy hermoso de Teixeira, de 1656, del cual reproduce, con todo acierto, muchas de sus iglesias. La gran característica del Madrid religioso del siglo xvil es la cúpula encamonada, es decir, de madera y yeso, cubierta, las más de las veces, con pizarra, que da el tono del paisaje arquitectónico. En los interiores se distinguen en Madrid las plantas de cruz latina -salvo la espléndida planta oval de San An- 
tonio de los Alemanes-, con los machones de la cúpula achaflanados, que da mayor amplitud espacial y grata perspectiva al presbiterio y cruceros. Otra modalidad muy madrileña es el uso de capillas laterales, sobre las cuales se abren balcones o tribunas, con tanto gusto que incluso a veces, como en la hoy Catedral de San Isidro, van en los paños de las interpilastras, haciendo un poderoso juego de vanos que sólo se ven en Madrid. Fueron también muy interesantes los atrios, Ionjas o compases, que de las tres maneras se llaman, que sirvieron para dar realce y vista a las fachadas y para otras dos funciones fenecidas hoy: evitar la entrada de animales y de "mentideros" o lugar de chismografía dominguera. Las fachadas madrileñas son, en general, muy severas, siguiendo la elegante sencillez de la Encarnación o de las Descalzas Reales. "En Madricl - dice Bonet Correa- se crean tipos característicos como el altar exento o baldaquino... el hernano Bautista fue el primero que, bajo la influencia del túmulo de Margarita de Austria, obra del Greco, empleó este tipo..." El origen de los baldaquinos creemos que es algo más antiguo que una pira funeraria, por más que sea del Greco. Tanto el genial pintor, como Bautista, como Bernini, tenían tras de sí una colosal tradición de ciborios, pero eso no impide que, de manera directa e inmediata, el jesuita Bautista se inspirase en el túmulo. Nos interesa una frase sobre el todavía menospreciado José de Churriguera: "No sólo desarrollo el tipo barroco de sus antecesores, sino que, con sus últimas obras, ya en el primer tercio del siglo xvil, dio nuevos rumbos al arte del retablo" (p. 24). El magnifico librito de Antonio Bonet Correa, junto con el anterior de Alberto Tamayo, Iglesias Barrocas madrileñas, de 1946, son la mejor guia para el conocimiento de la historia y el arte de los antiguos templos de Madrid. Posteriormente, Bonet Correa, en Archivo Español de Arte, No 137, 1962, aumentó el estudio de Las Calatravas con la importante noticia de que sus retablos son la última obra de José Benito de Churriguera.

F. de la $\mathbf{M}$.

GASPARINI, GRAZiANo. La Casa Colonial Venezolana. Centro de estudiantes de arquitectura. Universidad Central de Venezuela. Caracas, 1962.

Inusitada novedad es la que ofrece este estudio del arquitecto Graziano Gasparini, sobre las casas coloniales venezolanas, un aspecto tan desconocido del arte hispanoamericano, como lo era la arquitectura religiosa de ese país, antes de que el propio Gasparini la presentara en su magnifico libro Templos Coloniales de Venezuela, (Caracas, 1959).

No obstante que las casas coloniales de Venezuela que han sobrevivido hasta nuestros días, corresponden en su mayoría al siglo xviIr, el autor ha podido realizar un estudio sobre la transformación de la vivienda de tipo español, descle el siglo de la conquista hasta años muy posteriores a la liberación nacional. En el estudio no se olvidan, por supuesto, los antecedentes autóctonos, máxime cuando estos tanta im. 
portancia tuvieron en la nueva arquitectura con la cual se integraron, en algunos casos, de manera decisiva. Los antecedentes prehispánicos de la casa venezolana son diversos, según sean las regiones geográficas y las condiciones sociales existentes; Jos ejemplos van desde las habitaciones colectivas, situadas en plena selva, hasta las de tipo palafítico; y a excepción de la región andina, donde se empleó la piedra, en las otras regiones se impusieron de manera general, tanto los materiales como los sistemas constructivos: estructuras de horcones, cañas, bejucos, paja y ticrra.

Con un criterio muy equilibrado Gasparini hace el estudio de lo que nosotros liamaremos la casa tradicional de Venezuela. Para él, esta casa es el producto del mestizaje habido, tanto biológica como culturalmente, entre lo peninsular y lo autóctono, si bien no deja de reconocer que el mestizaje se impuso de manera más amplia, en las zonas limitadas a la penetración colonial, en tanto que lo autóctono persistió en las incógnitas regiones que forman el pais, persistencia que ha llegado, inclusive, hasta nuestros dias; de ahí lo tradicional que se encuentra en esta arquirectura. Una creación estética con valores propios, es la que ve Gasparini en las obras que produjo el mestizaje, y por ello se rebela contra quienes ven en lo mestizo o "popular", como también se le denomina, una manifestación inferior de cultura. Sus argumentos, parte medular de su estudio, convencen ampliamente y contribuyen a la comprensión artística de esta arquitectura.

Las casas coloniales de Venezuela se dividen en urbanas y rurales, no existen los modelos metropolitanos de gran mansión señorial; es decir, idénticas son las casas de Caracas a las de las pequeñas poblaciones del interior. "Ias características de las casas urbanas se repiten en cuanto a distribución y estética. En la fachada se concentró la exteriorización del gusto y las posibilidades económicas. Alrededor del patio interior se desenvolvió la vida diaria y la intimidad familiar. En las casas rurales, el espacio exterior dictó nuevas necesidades y los corredores rodearon la construcción. . Faltan palacios de piedra y casas suntuosas, porque no hubo riqueza minera y la agricultura puso límites a las posibilidades constructivas. Arquitectura modesta, más humana y en perfecta escala con el medio. No actuaron arquitectos famosos, si buenos alarifes y maestros... Hubo armonía volumétrica en pueblos y ciudades; sinceridad en la forma de vida y coherencia expresiva".

Tras de esta sintesis sobre lo esencial de la casa venezolana, Graziano Gasparini estudia, en extensos apartados, tanto los exteriores como los interiores de las viejas habitaciones coloniales; sus diversos elementos de construcción, así como los adornos y las soluciones adecuadas al medio, son prolijamente analizados. Pero si sus investigaciones pacientes y metódicas nos llevan al conocimiento de una arquitectura digna de ser admirada y por tanto conservada, por otra parte, su trabajo resulta desalentador ante el penoso espectáculo y las referencias que ofrece respecto a la destrucción que se ha cometido con gran número de esos monumentos. El mal, ya lo sabemos, no es imputable únicamente a Venezuela, es una endemia que ha atacado a los pueblos hispanoamericanos, pueblos ayunos de conciencia histórica y de fe en sus ricas posibilidades espirituales; pero cuánto más sentimos que se destruyan, por fines bastardos y pasajeros al arte de un pueblo, los escasos monumentos que están testimotiiando un pasado no exento, precisamente, de gloria, ante un presente muchas ocasiones incierto.

En la historia de la arquitectura venezolana, Graziano Gasparini es la máxima autoridad; el estudio que hoy nos ha entregado sobre la casa tradicional venezolana, 
es sencillamente, ejemplar, y nos hace pensar en la urgente necesidad que existe respecto a otros países hispanoamericanos que están en espera de trabajos similares. Y como de Gasparini aún es mucho lo que esperamos, ojalá no esté lejana la fecha en la que nos ofrezca un estudio sobre la arquitectura militar de la vieja capitanía, con él cerrará la historia arquitectónica de Venezuela en su periodo colonial. Hoy en dia los mejores libros de arte impresos en Hispanoamérica, salen de las prensas venezolanas; no hay exageración en lo dicho, en todo caso la impecable presentación cle este libro confirma nuestras palabras.

X. M.

WETHEY, HAROLD E. Arquitectura $V i$. rreinal en Bolivia. Recopilación y traducción de José de Mesa y Teresa Gisbert. Instituto de Investigaciones Artisticas. Facultad de Arquitectura. Universidad Mayor de San Andrés. La Paz, 1960.

Autoridad de reconocida valía en los estudios del arte español c hispanoamericano, es la del profesor Harold E. Wethey, para detenernos aquí en una presentación que en nada más contribuiría al sólido prestigio intelectual que ha alcanzado con la publicación de las diversas obras que cuentan a su haber. Este trabajo suyo que hoy reseñamos, está dedicado al estudio de la arquitectura colonial boliviana y viene a ser, en cierta forma, la continuación del volumen que dedicó, en 1949, a la arqui. tectura y escultura del Perú; por razones obvias una obra y otra se complementan, toda vez que durante el periodo colonial, Bolivia y Perú formaron una sola entidad, tanto en lo espiritual como en lo político, dicho esto en el sentido más amplio y generoso. Por causas que no son del caso señalar, los diversos capítulos de este libro aparecieron primero en varias revistas especializadas en arte, mas, con buen juicio, fueron reunidos y presentados en este volumen, gracias al empeño y esfuerzo ejemplar de los arquitectos e historiadores de arte, José de Mesa y Teresa Gisbert, traductores, además, de buena parte de los capitulos.

Con disciplinada erudición Wethey entrega en siete capitulos sus estudios sobre la arquitectura boliviana, si bien conviene advertir que uno de ellos está dedicado a los retablos de madera; sin embargo, la unidad no se pierde con ello, si se tiene presente que los retablos eran estructurados en forma arquitectónica a semejanza de las portadas de tantas iglesias virreinales, según el estilo artistico en boga. La arquitectura del siglo Xvr, que casi ha desaparecido, es analizada en sus diversos elementos y características, gracias a las noticias documentales existentes y a los contados edificios que han sobrevivido a la acción de los elementos naturales y a la destrucción de los hombres. Las notas principales en las obras de este siglo, se encuentran en el mudejarismo predominante, en la presencia de elementos góticos y en la obligada influencia del arte renacentista. El atrio y las capillas posas, como en México, también se utilizaron ya desde esa centuria. 
"El principal centro boliviano de la arquitectura colonial en el siglo xvir, es Sucre"; según el autor, los monumentos de la vieja Chuquisaca poseen una serie de valores que vienen a otorgarle una personalidad peculiar a la arquitectura de la ciudad que fuera asiento de la célebre Audiencia de Charcas; de esos edificios sobresale, por sus elementos constructivos y los alarifes que en ella intervinieron, la catedral; entre sus arquitectos destaquemos el nombre de un homónimo, casi contemporáneo, de nuestro Toribio de Alcaraz; en lo constructivo conviene señalar la preciosa y ejemplar cúpula elíptica que cubre el bautisterio. San Lorenzo y San Francisco, son otros monumentos valiosos de la arquitectura manierista y barroca que apareció en Sucre en el siglo xvir.

Sin lugar a dudas la manifestación estética más importante del arte virreinal sudamericano, lo constituye el estilo mestizo que floreció (partiendo de Arequipa) en el siglo xvin en las poblaciones aledañas al legendario Lago Titicaca y parte del territorio de la actual Bolivia. Dos centros de importancia, para el arte mestizo boliviano, señala el profesor Wethey: Potosi y La Paz. No vamos a repetir sus ideas respecto al arte mestizo, por ser éstas de orden general; si señalaremos, en cambio, las notas más sobresalientes que él ha encontrado en esta manifestación artística: "El arte mestizo, en cuanto a la arquitectura del sur del Perú y Bolivia, es un estilo exclusivamente decorativo. Debemos insistir en que no tiene ningún carácter estructural... Las plantas, elevaciones, bóvedas y la misma concepción de la arquitectura religiosa son de origen español-europeo... El carácter estructural de la arquitectura mestiza ... es el barroco español. Se usa la piedra aún en las bóvedas... En algunos casos (las iglesias) están tan monumentalmente construidas que recuerdan las edificaciones románicas... Las fachadas de las iglesias presentan tipos europeos reinterpretados de manera muy original, principalmente en la aplicación del ornamento... La columna salomónica es el rasgo más caracteristico de las fachadas del siglo xvili en Potosí y en La Paz... Dentro de la técnica, el aspecto más significativo de la talla mestiza es su calidad geométrica y planiforme. Esta tendencia consiste en tallar duramente la piedra en vez de modelarla a la manera clásica o renacentista..." Hecho el análisis de las principales características del arte mestizo, Wethey realiza el estudio de un buen número de iglesias para presentarnos, finalmente, los monumentos cumbres de este estilo en Bolivia; el primero es, la portada de San Lorenzo en Potosí, de la cual asienta que "la piedra fue tallada como una filigrana (y que) no tiene paralelo en el arte colonial. Los dibujos son exquisitos y delicados. Los motivos tallados en piedra parecen aplicaciones de oro y plata revelando una técnica de primer orden". El otro monumento sobresaliente es la iglesia de los franciscanos de La Paz, si bien Wethey se apresura a indicar que el estilo mestizo de aquí, proviene "de la escuela de Juli y Pomata, a orillas del Lago Titicaca".

Otros interesantes aspectos de la arquitectura colonial de Bolivia, merecieron la cuidadosa atención de Harold E. Wethey. La última fase de esta arquitectura la estudia en los monumentos de Cochabamba, Sucre y Potosi. El rococó, aunque de manera contenida, viene a suplantar la vitalidad decreciente del barroco, y el neoclasicismo se encargará de liquidar por completo, las fastuosidades decorativas de un estilo que adquirió personalidad propia: el barroco mestizo. De esta parte, sólo quiero destacar la iglesia de las carmelitas de Cochabamba, por la singular planta de forma polilobulada que se le dio inicialmente; como es sabido este tipo de plantas fue pocas ocasiones utilizado en la arquitectura hispanoamericana, de ahí la singulariclad que hay en este monumento. 
Al cerrar el estudio de la arquitectura religiosa, Wethey, en apretado y sustancioso resumen, nos entrega las notas más sobresalientes que encontró en la arquitectura civil boliviana; partiendo de la planificación de las poblaciones, estudia descie las sencillas habitaciones, hasta los grandes edificios que la nobleza, el clero, los ricos y el poder real levantaron, durante tres centurias, en aquellas latitudes.

Los estudios de arquitectura colonial boliviana de Harold E. Wethey, se cierran con un apéndice en el que incluye una serie de noticias documentales sobre un arquitecto llamado Toribio de Alcaraz, quien trabajó en Chuquisaca y Potosí entre 1549 y 1573, habiendo estado con anterioridad, 1543-1544, en Arequipa. Ahora bien, en la primera mitad del siglo xvi aparece en México, un arquitecto que lleva el mismo nombre y cuyas obras están en relación con las disposiciones constructivas que para los conventos e iglesias recomendaba, a su sucesor, el primer virrey cle la Nueva España, don Antonio de Mendoza. Don Manuel Toussaint atribuyó al Alcaraz que trabajó en México, las iglesias de una sola nave y dio como obra suya la iglesia franciscana de Cholula, Puebla. Del Alcaraz que construyó en Sudamérica, no se conoce obra alguna. Este caso, que no deja de ser curioso, no es más que una coincidencia de nombres y profesiones, puesto que "la superposición de fechas excluye la posibilidad de que sea un mismo arquitecto (el) que trabajó en Míxico y en el Perú y Bolivia".

Dadas las circunstancias en que muchas veces tienen que trabajar los editores hispanoamericanos, un esfuerzo encomiable fue el que realizó en la publicación de este libro, el Instituto de Investigaciones Artísticas, de la Universidad Mayor de San Andrés, de La Paz, Bolivia; Instituto que con singular dedicación dirige el arquitecto José de Mesa. Esta contribución a la Historia del Arte de América, merece la más elogiosa bienvenida.

X. M. 